\title{
Biosorption of methylene blue from aqueous solution by agricultural bioadsorbent corncob
}

\author{
Hee-Jeong Choi ${ }^{\dagger}$, Sung-Whan Yu \\ Department of Health and Environment, Catholic Kwandong University, Gangneung 25601, Republic of Korea
}

\begin{abstract}
Using the abandoned agricultural by-product corncobs, the most commonly used methylene blue (MB) dyestuffs were removed. This experiment is very meaningful because it is the recycling of resources and the use of environmentally friendly adsorbents. According to the Hauser ratio and porosity analysis, the corncob has a good flow ability of the adsorbent material and many pores, which is very advantageous for $\mathrm{MB}$ adsorption. As a result of the experiment, $\mathrm{MB}$ concentration of less than $0.005 \mathrm{~g} / \mathrm{L}$ was very efficiently removed with $10 \mathrm{~g} / \mathrm{L}$ of bioadsorbent corncob and the maximum adsorption capacity of corncob for MB dyes was obtained at $417.1 \mathrm{mg} / \mathrm{g}$. In addition, adsorption process of $\mathrm{MB}$ onto corncob was a physical process according to adsorption energy analysis. Corncob can efficiently and environmentally remove $\mathrm{MB}$ in aqueous solution, and is very cost effective and can recycle the abandoned resources.
\end{abstract}

Keywords: Adsorption, Agricultural waste, Corncob, Dye removal, Kinetics, Methylene blue

\section{Introduction}

Dyes are used in many industries closely related to human life such as textiles, leather products, paper, and plastics [1]. Today, more than 10,000 dyes are commercially available. The amount of dye wastewater generated annually worldwide is estimated to be about 750,000 tons [2]. The number of textile companies in Korea related to dyeing is 360,616 in 2015 , equivalent to $3.6 \%$ of total wastewater discharging facilities. However, dyeing wastewater emission accounts for $22.2 \%$ of total wastewater emission. Moreover, the organic matter load from dyeing wastewater is $2,134,429 \mathrm{~kg} / \mathrm{d}$, corresponding to $24.3 \%$ of total wastewater discharge [3, 4]. For this reason, dyeing wastewater is classified as a representative pollution from industry. Most dyes have complex and stable structures such as aromatic structures. Therefore, they are difficult to be decomposed by chemical, physical, or biological treatment [5]. When these dyestuffs are discharged without treatment, chromaticity can cause aesthetic discomfort. In addition, the dye can interfere with sunlight penetration of water surface, thereby deteriorating photochemical and biological activities of aquatic plants [2]. Dyes also have the potential to cause groundwater contamination, posing poten- tial threat to assimilation of organisms [4, 6]. Methylene blue (MB) is one inexpensive cationic dye widely used for dyeing cotton, wool, silk, leather, and coating paper [7]. Among various dyes classified, cationic dyes are known to be more toxic than other dyes. Although $\mathrm{MB}$ is not more toxic compared to other cationic dyes, long-term exposure to $\mathrm{MB}$ can cause serious health problems such as increased heart rate, vomiting, shock, cyanosis, jaundice, limb paralysis, mental confusion, eye burns, and tissue necrosis [8]. To reduce the impact of $\mathrm{MB}$ on the environment, animals, and plants, $\mathrm{MB}$ contaminated wastewater should be treated before being discharged into water environment.

Currently, dye wastewater is treated by various methods such as ozone oxidation treatment, coagulation treatment, advanced oxidation (AOP), and biological treatment [9]. The coagulation process is effective in removing insoluble dyes such as disperse dyes. However, it is ineffective for soluble dyes with disadvantage of producing large amounts of sludge [10]. The ozone treatment process is effective for removing almost all dyes except disperse dyes. However, ozone is costly because it has a short half-life. It needs to be supplied continuously for dye removal [11]. Most known dye removal processes have low removal rates. Particularly, they have very low removal efficiencies for samples
This is an Open Access article distributed under the terms of the Creative Commons Attribution Non-Commercial License (http://creativecommons.org/licenses/by-nc/3.0/) which permits unrestricted non-commercial use, distribution, and reproduction in any medium, provided the original work is properly cited.

Copyright (C) 2019 Korean Society of Environmental Engineers
Received March 19, 2018 Accepted June 20, 2018

${ }^{\dagger}$ Corresponding author

Email: hjchoi@cku.ac.kr

Tel: +82-33-649-7297 Fax: +82-33-647-7635

ORCID: 0000-0003-3370-4277 
with low dye concentrations. On the other hand, the adsorption method is simple to operate and has high removal efficiency. Thus, it is widely used in the treatment of dye wastewater [12, 13]. However, activated carbon is expensive. Moreover, it needs additive materials to improve removal rate of inorganic substance [14].

In recent years, many researches have been actively carried out to remove dyeing wastewater and heavy metals using agricultural byproducts such as wheat straw [15], banana peel [16], pomelo peel [17], bagasse [18], rice husks [19], tea wastes [7], canola residues [10], cashew nut shell [20, 21], tamarind seed [22], and orange peel [23]. These studies have mainly used adsorbents by activating low-cost agricultural wastes or by-products. However, MB removal rate was low due to diffusion limitation and decreased surface active sites. Further, there is problem in the separation and removal of adsorbent after wastewater treatment and generation of secondary wastes. Therefore, it is necessary to develop an ecofriendly adsorbent that is inexpensive with increased adsorption for MB. In order to overcome these problems, corncob was used as a low-cost adsorbent to remove MB dye in this study.

Maize (Zea mays) is the world's third largest food crop after rice and wheat. Global corn production is estimated at over 1,016,431,000 tons per year in 2015 [24]. The amount of corncob wastes is increasing with increasing corn production. Corncob is one of the most agricultural wastes produced in the world. According to a previous report [25], $18 \mathrm{~kg}$ corncobs are generated when $100 \mathrm{~kg}$ of corn grains are produced. Therefore, the aim of this study was determine the adsorption rate of corncob for $\mathrm{MB}$ and compare the result with the adsorption rate reported by other researchers. In addition, adsorption kinetics and intraparticle diffusion were analyzed by applying pseudo-first-order and pseudo-second-order. Moreover, adsorption isotherms of Langmuir, Freundlich, and Dubinin-Radushkevich were investigated and thermodynamic analyses were carried out by adsorption experiments through temperature changes.

\section{Materials and Methods}

Agricultural waste adsorbent, corncobs, were collected from farms in Gangneung, Korea. After collection, corncobs were washed several times with deionized water to remove contaminants on the surface of corncob followed by drying in an oven at $70^{\circ} \mathrm{C}$ for $72 \mathrm{~h}$. Dried corncobs were cut into $0.5 \mathrm{~cm}$ in thickness and stored in a desiccator for experiments. $\mathrm{MB}$ $\left(\mathrm{C}_{16} \mathrm{H}_{18} \mathrm{~N}_{3} \mathrm{SCI}\right.$, Sigma Aldrich) is cationic dye and heterocyclic aromatic chemical compound.

In this experiment, stock solution of $\mathrm{MB}$ was prepared by dissolving $0.02 \mathrm{~g}$ of $\mathrm{MB}$ in $1 \mathrm{~L}$ of distilled water. Depending on the concentration of $\mathrm{MB}$ required for the experiment, it was diluted. Batch studies were conducted to investigate the effect of $\mathrm{pH}$, initial $\mathrm{MB}$ concentration, temperature, and initial corncob dosage on adsorption efficiency for $\mathrm{MB}$. $\mathrm{pH}$ and temperature were controlled from 2 to 10 using $\mathrm{HCl}$ and/or $\mathrm{NaOH}$ solution and from $10^{\circ} \mathrm{C}$ to $30^{\circ} \mathrm{C}$ using electrical thermostat, respectively, to effect adsorption of $\mathrm{MB}$ onto corncob. Different amounts of corncobs and $500 \mathrm{~mL}$ of $\mathrm{MB}$ solution were then added into a $1 \mathrm{~L}$ of conical flask and stirred with a magnetic bar at 200 rpm. Contents of these flasks were sampled at fixed intervals of time $(0,10,20,30,60,120,240,720$, and 1,440 min) and filtered through membrane filter (0.45 $\mu \mathrm{m}$, Whatman). Concentrations of $\mathrm{MB}$ dye remained in these filtered samples were analyzed using spectrophotometric method. All experiments were carried out by changing one parameter at a time while holding the others constant. Experiments were performed five times. Mean values and standard deviation were calculated.

Qualitative and quantitative analyses of inorganic components contained in corncob were performed using X-ray fluorescence (XRF) (XRF-1500, Shimadzu, Japan). Surface analysis was performed using Scanning electron microscope (SEM, SM-300) and Topcon, respectively. The measurements of ash content, porosity, particle density and Hausner ratio were in accordance with the measurement method published by Azubuike and Okhamafe [26]. The size of the corncob particles was measured using a particle size analyzer (Laser Diffraction Master class 3 \& 4, Malvern, England). The amount of corncob was measured with an electronic balance (XP26, Mettler Toledo, Swiss). The $\mathrm{pH}$ and temperature were measured using a $\mathrm{pH}$ meter (SevenGO pro, Mettler Toledo).

The adsorbed amount of MB by corncob was measured using UV-vis spectrophotometer (Shimadzu, MINI-1240) at $664 \mathrm{~nm}$, the maximum absorption wavelength of MB. The adsorption amount was calculated using the following equation:

$$
q_{t}=\frac{\left(C_{o}-C_{t}\right) V}{m}
$$

where $C_{o}(\mathrm{mg} / \mathrm{L})$ was the initial concentration of solution, $C_{t}$ $(\mathrm{mg} / \mathrm{L})$ was the concentration of solution at time $t, V(\mathrm{~L})$ was the volume of solution, and $m$ (g) was the amount of corncob.

Percentage removal of $\mathrm{MB}$ dye was calculated using the following equation:

$$
\% \text { Removal }=\frac{C_{o}-C_{F}}{C_{o}} \times 100
$$

where $C_{0}$ and $C_{F}$ were the initial and final concentration of $\mathrm{MB}$ dye in the solution, respectively.

\section{Results and Discussion}

\subsection{Characteristics of Corncob}

Regarding the content of dried corncob, there were $86.4 \mathrm{~g}$ of carbohydrate and $0.8 \mathrm{~g}$ of fat. Results of general composition analysis of the dried corncob are shown in Table 1. Fixed carbon represents the percentage of carbon remaining after subtracting the proportion of moisture, ash, and volatiles. Total carbon content of dried corncob was $58 \%$ and fixed carbon content was $38 \%$. Ash content plays an important role in the adsorption of electrolyte from solution when it is present in small amounts [26]. Results showed that the ash content of dried corncob was as low as $3 \%$. Contents of sulfur and nitrogen were also low 
Table 1. Elemental Analysis (wt, \% of Dried Material) and Physical Properties of Corncob

\begin{tabular}{|c|c|c|c|c|c|c|c|c|c|c|c|}
\hline Elements & C & $\mathbf{H}$ & $\mathbf{N}$ & S & $\begin{array}{c}\text { Moisture } \\
\text { residual }\end{array}$ & $\begin{array}{c}\text { Volatile } \\
\text { matter }\end{array}$ & $\begin{array}{c}\text { Ash } \\
\text { content }\end{array}$ & $\begin{array}{c}\text { Fixed } \\
\text { carbon }\end{array}$ & $\begin{array}{l}\text { Particle density } \\
\qquad\left(\mathrm{g} / \mathrm{cm}^{3}\right)\end{array}$ & $\begin{array}{l}\text { Hausner } \\
\text { ratio }\end{array}$ & Porosity \\
\hline wt. (\%) & $\begin{array}{c}57.81 \pm \\
0.2\end{array}$ & $\begin{array}{c}5.42 \pm \\
0.1\end{array}$ & $\begin{array}{c}0.83 \pm \\
0.01\end{array}$ & $\begin{array}{c}0.03 \pm \\
0.001\end{array}$ & $\begin{array}{c}1.42 \pm \\
0.1\end{array}$ & $\begin{array}{c}17.41 \pm \\
0.1\end{array}$ & $\begin{array}{c}3.23 \pm \\
0.1\end{array}$ & $\begin{array}{c}37.63 \pm \\
4.12\end{array}$ & $\begin{array}{c}1.47 \pm \\
0.02\end{array}$ & $\begin{array}{c}0.893 \pm \\
0.004\end{array}$ & $\begin{array}{c}83.51 \pm \\
0.86\end{array}$ \\
\hline
\end{tabular}

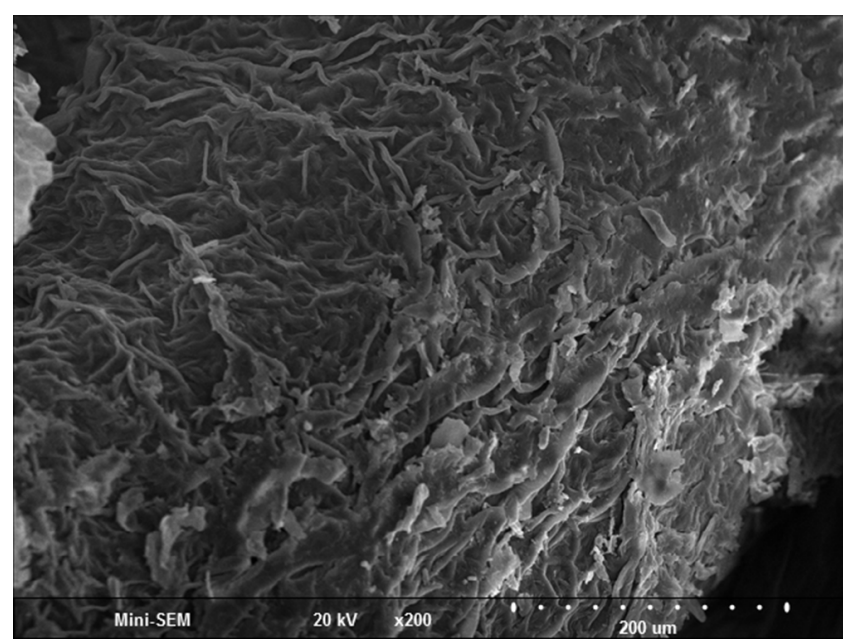

Fig. 1. SEM image of corncob.

as $0.03 \%$ and $0.83 \%$, respectively. Therefore, nitrogen and sulfur based functional groups are not expected to affect the adsorption of MB by corncob. The Hausner ratio can be used to estimate cohesion between particles. A Hausner ratio of less than 1.20 indicates good flow ability, and a value higher than 1.50 indicates poor flow properties [26]. The Hausner ratio of corncob in this study was determined 0.893, indicating good flow ability of the adsorbent material. The porosity of the adsorbent is another criterion for selecting good adsorbents. The porosity of the corncob used in this experiment was measured around 83.5\%, indicating very high porosity, which is expected to have a good effect on adsorption of $\mathrm{MB}$.

SEM image of corncob is shown in Fig. 1. The surface of corncob was very irregular and porous in nature (Fig. 1). These porous and irregular surfaces are thought to be very helpful for adsorbing $\mathrm{MB}$ dye [24]. In addition, the surface of the corncob was composed of multiple layers of thin films. This can be useful to adsorb heavy metals and dyes [13].

\subsection{Effect of Different Parameters on MB Removal}

\subsubsection{Effect of initial MB concentration}

The initial $\mathrm{MB}$ dye concentration affords an important driving force in overcoming mass transfer resistance between the corncob surface and MB dye solution. The effect of initial dye concentration on the removal of $\mathrm{MB}$ dye by corncob is shown in Fig. 2(a). The adsorption rate, adsorption capacity, and the cost of the adsorbent are very important factors in the selection of adsorbent. The amount of adsorbent is also important in terms of cost. The ability to adsorb and remove large quantities of harmful substances with a small amount of adsorbent has many economic advantages. Therefore, in this experiment, we investigated the
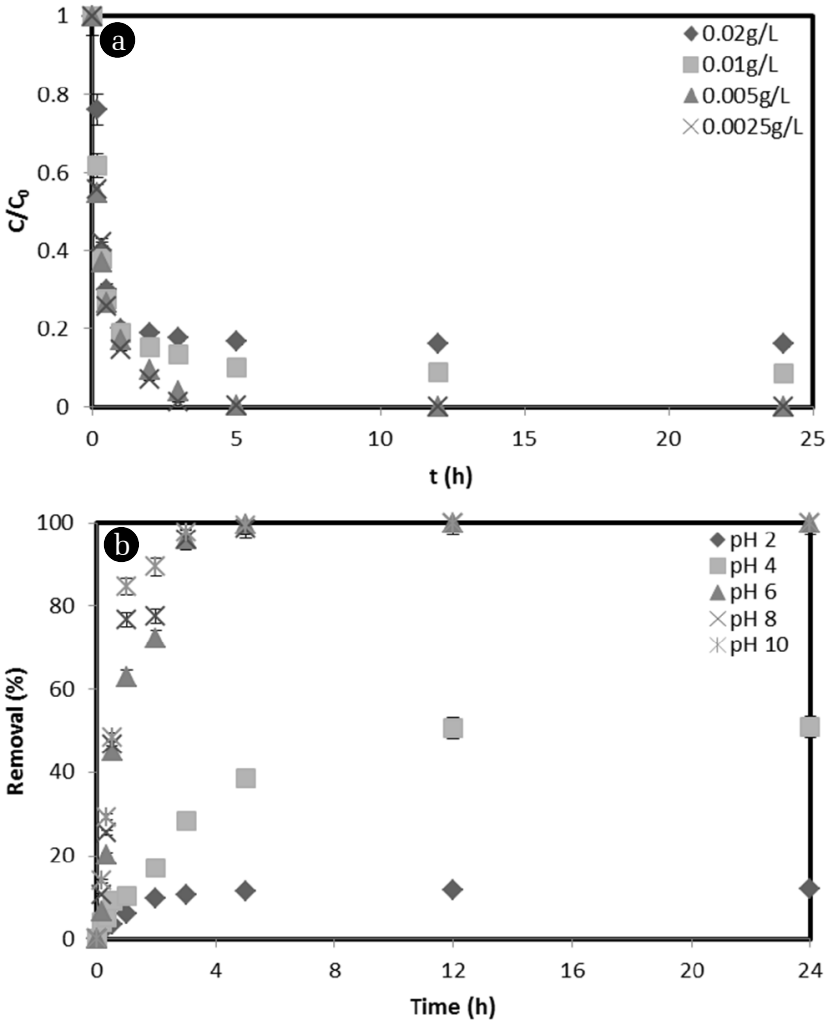

Fig. 2. (a) Effect of contact time (Corncob $=10 \mathrm{~g} / \mathrm{L}$, Agitation $=150$ rpm, Temperature $=30^{\circ} \mathrm{C}, \mathrm{pH}=6$ ), (b) Effect of $\mathrm{pH}$ on the adsorption of $\mathrm{MB}($ Corncob $=10 \mathrm{~g} / \mathrm{L}, \mathrm{MB}$ concentration $=0.005$ $\mathrm{g} / \mathrm{L}$, Agitation $=150 \mathrm{rpm}$, Temperature $=30^{\circ} \mathrm{C}$.

concentration of $\mathrm{MB}$ that could be removed by corncob adsorbent. Corncob $10 \mathrm{~g} / \mathrm{L}$ was added to various concentrations of $\mathrm{MB}(0.02$ $\mathrm{g} / \mathrm{L}, 0.01 \mathrm{~g} / \mathrm{L}, 0.005 \mathrm{~g} / \mathrm{L}$, and $0.0025 \mathrm{~g} / \mathrm{L}$ ) in solution. The effect of $\mathrm{MB}$ concentration on its removal rate was observed for 24 h. In 3 h, corncob removed $82.46 \%$, 86.79\%, 96.01\%, and 98.62\% of $\mathrm{MB}$ at $\mathrm{MB}$ concentrations of $0.02 \mathrm{~g} / \mathrm{L}, 0.01 \mathrm{~g} / \mathrm{L}, 0.005 \mathrm{~g} / \mathrm{L}$, and $0.0025 \mathrm{~g} / \mathrm{L}$ in aqueous solution, respectively (Fig. 2(a)). The percentage removal of $\mathrm{MB}$ dye was decreased gradually with an increase of MB dye concentration from 0.0025 to $0.02 \mathrm{~g} / \mathrm{L}$. This is because the capacity of corncob capable of adsorbing $\mathrm{MB}$ is sufficient for low concentration of MB dye. This could decrease the adsorption capacity of corncob at higher concentration of $\mathrm{MB}$ dye. Therefore, the removal percentage of $\mathrm{MB}$ was decreased when $\mathrm{MB}$ dye concentration was increased.

After $3 \mathrm{~h}$, the removal rate of MB by corncob was not significantly changed. Adsorption equilibrium was reached in 5 h. After $24 \mathrm{~h}$, the percentage of $\mathrm{MB}$ adsorbed onto corncob was found to be $84.05 \%, 91.48 \%, 99.90 \%$, and $99.97 \%$ for $0.02 \mathrm{~g} / \mathrm{L}$, 
$0.01 \mathrm{~g} / \mathrm{L}, 0.005 \mathrm{~g} / \mathrm{L}$, and $0.0025 \mathrm{~g} / \mathrm{L}$ of $\mathrm{MB}$, respectively. According to experimental results, $\mathrm{MB}$ concentration below $0.005 \mathrm{~g} / \mathrm{L}$ could be removed almost $100 \%$ with $10 \mathrm{~g} / \mathrm{L}$ corncob.

\subsubsection{Effect of $\mathrm{pH}$}

$\mathrm{pH}$, alkalinity, stirring conditions, and static materials are main influential factors in the adsorption and removal of oil and inorganic materials in aqueous solution. In particular, temperature and $\mathrm{pH}$ of aqueous solution can greatly influence the removal of dyes [27]. To investigate the effect of $\mathrm{pH}$ on $\mathrm{MB}$ removal rate, $\mathrm{pH}$ was controlled at $2,4,6,8$, and 10 . The removal rate of $\mathrm{MB}$ by corncob was $11.47 \%$ at $\mathrm{pH} 2,38.46 \%$ at $\mathrm{pH} 4,99.74 \%$ at $\mathrm{pH} 6,99.89 \%$ at $\mathrm{pH}$, and $99.90 \%$ at $\mathrm{pH} 10$ (Fig. 2(b)). The adsorption of $\mathrm{MB}$ using corncob depended strongly on the $\mathrm{pH}$ of the aqueous solution. This is because the $\mathrm{pH}$ of the solution is affected by dissolved state of $\mathrm{MB}$ in aqueous solution and surface charge distribution of the corncob. That is, the $\mathrm{pH}$ can affect the electrostatic interaction of the type of $\mathrm{MB}$ in the aqueous solution and the rebound characteristics between surfaces of the corncob. $\mathrm{MB}$ is present in aqueous solution as cationic species as undissociated molecules. At $\mathrm{pH} 3$, undissociated molecules of $\mathrm{MB}$ predominate at $86 \%$, with $50 \%$ of cationic species and undissociated molecules at $\mathrm{pH}$ 4. Only cationic species of $\mathrm{MB}$ are present at $\mathrm{pH} 6$ or above [28]. That is, the higher removal rate at higher $\mathrm{pH}$ is due to increased anion in the aqueous solution as $\mathrm{pH}$ increases, making it easier to adsorb $\mathrm{MB}$ present as cationic species.

\subsection{Adsorption Kinetics by Corncob}

The kinetic mechanism for the adsorption of MB dye by corncob plays an important role in the adsorption process. It provides important information about the reaction pathway and the rate-controlling mechanism of exchange reactions [10]. In the present study, pseudo-first-order, pseudo-second-order, and intra-particle diffusion were used to examine the adsorption and diffusion rates of $\mathrm{MB}$ by corncob. Pseudo-first-order reaction depends only on the concentration of one reactant (a single-molecule reaction). Other reactants might be present. However, each will be in zero order. Pseudo-second-order reaction depends on the concentration of one second order reactant or two first order reactants. The calculated experiment data are shown in Fig. 3(a) and (b), and adsorption kinetics parameters are shown in Table 2. Among all models, calculated adsorption capacity values of pseudo-second-order models were the closet to

Table 2. Kinetic and Isotherm Data for the Adsorption of MB by Corncob

\begin{tabular}{|c|c|c|c|c|}
\hline \multirow{3}{*}{ Pseudo-first-order } & \multirow{3}{*}{$\ln \left(q_{e}-q_{t}\right)=\ln q_{e}-k_{1} t$} & $\mathrm{k}_{1}\left(\min ^{-1}\right)$ & \multicolumn{2}{|c|}{0.227} \\
\hline & & $\mathrm{q}_{\mathrm{e}}(\mathrm{mg} / \mathrm{g})$ & \multicolumn{2}{|c|}{131.61} \\
\hline & & $r^{2}$ & \multicolumn{2}{|c|}{0.8327} \\
\hline \multirow{3}{*}{ Pseudo-second-order } & \multirow{3}{*}{$\frac{t}{q_{t}}=\frac{1}{k_{2} q_{e}^{2}}+\frac{t}{q_{e}}$} & $\mathrm{k}_{2}(\mathrm{~g} / \mathrm{mg} \min )$ & \multicolumn{2}{|c|}{0.0763} \\
\hline & & $\mathrm{q}_{\mathrm{e}}(\mathrm{mg} / \mathrm{g})$ & \multicolumn{2}{|c|}{405.22} \\
\hline & & $\mathrm{r}^{2}$ & \multicolumn{2}{|c|}{0.9968} \\
\hline \multirow{2}{*}{ Intra-particle diffusion } & \multirow{2}{*}{$q_{t}=k_{d} t^{\frac{1}{2}}+I$} & $\mathrm{k}_{\mathrm{d}}\left(\mathrm{mg} / \mathrm{g} / \mathrm{h}_{0.5}\right)$ & \multicolumn{2}{|c|}{53.56} \\
\hline & & $r^{2}$ & \multicolumn{2}{|c|}{0.7801} \\
\hline \multirow{3}{*}{ Langmuir } & \multirow{3}{*}{$\frac{C_{e}}{q_{e}}=\frac{1}{K_{L} q_{m}}+\frac{C_{e}}{q_{m}}$} & $\mathrm{q}_{\mathrm{m}}(\mathrm{mg} / \mathrm{g})$ & \multicolumn{2}{|c|}{417.12} \\
\hline & & $\mathrm{k}_{\mathrm{L}}(\mathrm{L} / \mathrm{g})$ & \multicolumn{2}{|c|}{1.40} \\
\hline & & $r^{2}$ & \multicolumn{2}{|c|}{0.998} \\
\hline \multirow{3}{*}{ Freundlich } & \multirow{3}{*}{$\ln q_{e}=\frac{1}{n} \quad \ln C_{e}+\ln K_{F}$} & $\mathrm{n}$ & \multicolumn{2}{|c|}{3.108} \\
\hline & & $\mathrm{k}_{\mathrm{F}}(\mathrm{mg} / \mathrm{g})(\mathrm{g} / \mathrm{L})^{1 / \mathrm{n}}$ & \multicolumn{2}{|c|}{15.62} \\
\hline & & $\mathrm{r}^{2}$ & \multicolumn{2}{|c|}{0.913} \\
\hline \multirow{3}{*}{ Dubinin-Radushkevich } & \multirow{3}{*}{$\begin{array}{l}q_{e}=q_{m} \exp \left(-K_{D^{\varepsilon_{p}}}\right) \\
E=\frac{1}{\sqrt{2 \beta}}\end{array}$} & $\ln \mathrm{q}_{\mathrm{m}}(\mathrm{mol} / \mathrm{g})$ & \multicolumn{2}{|c|}{-6.639} \\
\hline & & $\mathrm{E}(\mathrm{kJ} / \mathrm{mol})$ & \multicolumn{2}{|c|}{3.352} \\
\hline & & $\mathrm{r}^{2}$ & \multicolumn{2}{|c|}{0.8046} \\
\hline \multirow{5}{*}{ Themodynamic parameters } & \multirow{5}{*}{$\triangle \mathrm{G}^{0}(\mathrm{~kJ} / \mathrm{mol})=\triangle \mathrm{H}^{\circ}-\mathrm{T} \triangle \mathrm{S}^{\circ}$} & $\triangle \mathrm{H}^{0}(\mathrm{~kJ} / \mathrm{mol})$ & \multicolumn{2}{|c|}{18.12} \\
\hline & & $\triangle \mathrm{S}^{0}(\mathrm{~J} / \mathrm{mol} \cdot \mathrm{K})$ & \multicolumn{2}{|c|}{0.1057} \\
\hline & & & $293 K$ & -13.41 \\
\hline & & $\triangle \mathrm{G}^{0}(\mathrm{~kJ} / \mathrm{mol})$ & $303 \mathrm{~K}$ & -14.99 \\
\hline & & & $313 \mathrm{~K}$ & -16.58 \\
\hline
\end{tabular}

where $q_{\mathrm{t}}$ and $q_{\mathrm{e}}$ are the amount of adsorbed crude oil at time $(t)$ and equilibrium, respectively. $k_{1}$ and $k_{2}$ are the pseudo-first-order and pseudo-second-order rate constant, respectively. $K_{\mathrm{d}}$ is the intra-particle diffusion rate constant $\left(\mathrm{meq} / \mathrm{g} \cdot \mathrm{h}_{0.5}\right)$ and $I$ is the intercept. $q_{\mathrm{e}}(\mathrm{mg} / \mathrm{g})$ represents the sorption capacity at equilibrium, $C_{e}$ is the equilibrium concentration in the solution, $q_{\mathrm{m}}(\mathrm{mg} / \mathrm{g}$ ) is the maximum adsorption capacity, and $K_{\mathrm{L}}(\mathrm{L} / \mathrm{mg})$ is the Langmuir adsorption equilibrium constant. $K_{\mathrm{F}}$ is the constant that represents adsorption capacity related to bond strength, and $1 / n$ is the constant indicating adsorption intensity. $K_{\mathrm{F}}$ and $\mathrm{n}$ can determined from the linear plot of $\ln q_{\mathrm{e}}$ vs. $\ln C_{e} . K_{\mathrm{D}}\left(\mathrm{mol}^{2} / \mathrm{kJ}^{2}\right)$ is the D-R model constant related to the free energy of adsorption, $\mathcal{E}^{\mathcal{E}}$ is polanyi potential ( $\mathcal{E}^{\mathcal{E}}$ $=$ RT In $\left(1+1 / C_{\mathrm{e}}\right)$, and $E(\mathrm{~kJ} / \mathrm{mol})$ is the average adsorption energy. $\Delta \mathrm{G}^{\circ}, \Delta \mathrm{H}^{\circ}, \Delta \mathrm{S}^{\circ}$, and $\mathrm{T}$ are Gibbs free energy, enthalpy, entropy, and absolute temperature in kelvin $(\mathrm{K})$, respectively. 

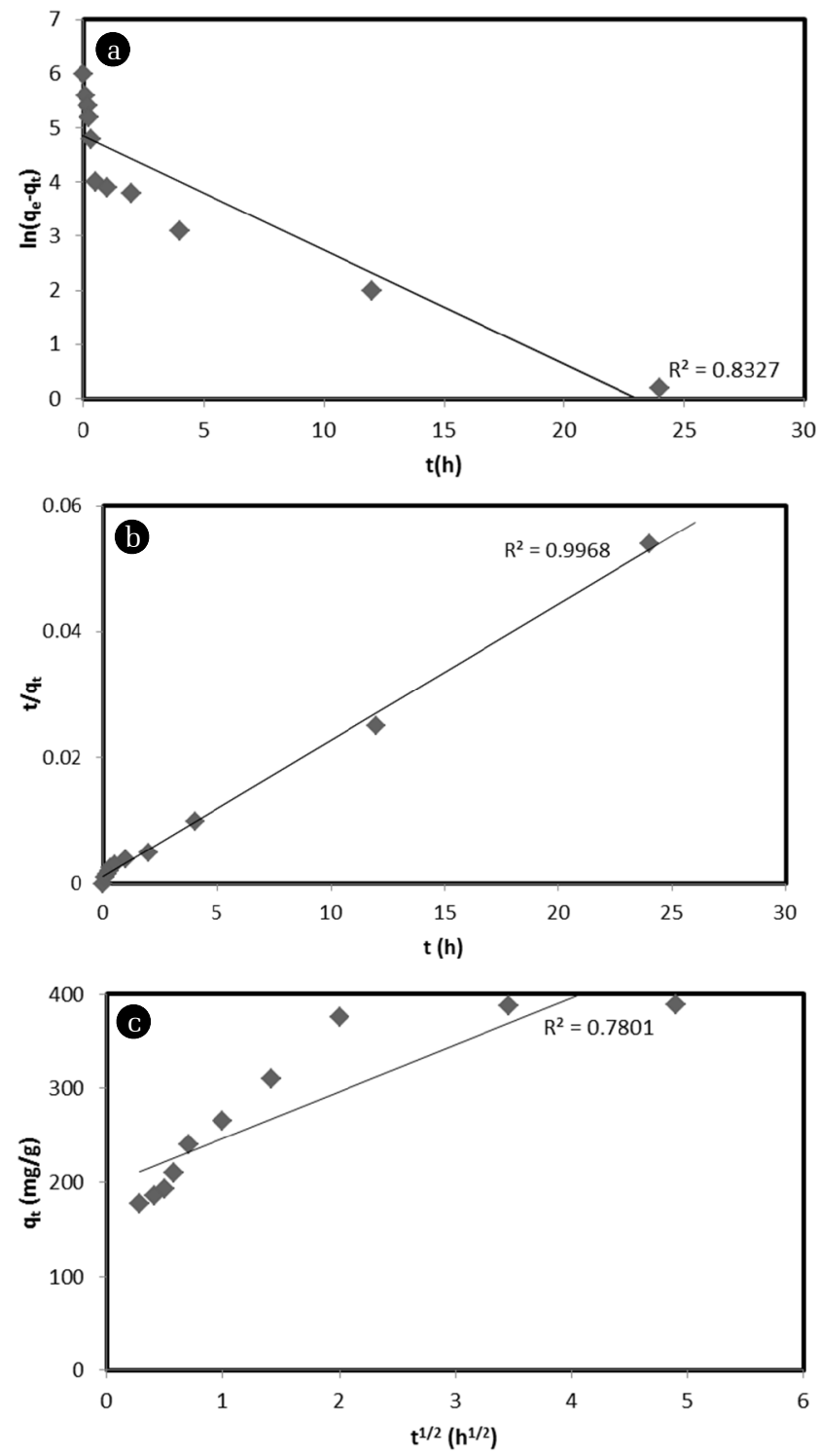

Fig. 3. (a) Pseudo-first-order, (b) Pseudo-second-order kinetics, and (c) Intra-particle diffusion for the adsorption of MB.

experimental adsorption capacity. In addition, the coefficient of determination $\left(\mathrm{R}^{2}\right)$ was found to be 0.8327 for pseudo-first-order model and 0.9968 for pseudo-second-order model when adsorption data of MB by corncob were applied. Therefore, the pseudo-second-order kinetic model had a better fit for experimental data compared to pseudo-first-order kinetic model considering its higher correlation coefficient value. This suggests that adsorption process is controlled by sorption between molecules of $\mathrm{MB}$ dye and the surface of corncob. Moreover, results showed that the rate of adsorption depended on the availability of adsorption sites on the surface of corncob rather than the number of adsorbed MB dye molecules. Fig. 3(c) shows the result when the internal particle diffusion model of equation is applied. It shows that data do not have a linear relationship. These results suggest that the adsorption process of MB dye on corncob occurs with complex mechanisms involving external mass transfer and internal particle diffusion. As shown in Fig. 3(c), mass transfer occurs in the adsorption initial region (linear region of $t_{1 / 2}<1.7$ ). Then it occurs in subsequent linear region (linear region of $t_{1 / 2}>1.7$ ) as an adsorption process involving internal particle diffusion. The intra-particle diffusion rate constant of MB obtained from the slope of equation was at 53.56 $\mathrm{mg} / \mathrm{g} / \mathrm{h}_{0.5}$.

\subsection{Adsorption Isotherm}

Interaction between adsorbate and adsorbent surface, maximum adsorption capacity of the adsorbent material, and dynamic equilibrium of adsorption system were investigated using the adsorption isotherm model. It has been reported that the best fitted adsorption isotherm model can provide information about the nature of the adsorption system [2]. In this adsorption study, three parameter models (Langmuir, Freundlich model, and Dubinin-Radushkevich) were used to fit with experimental data to estimate the best fitted isotherm model. Results of applying equations to data obtained from equilibrium adsorption experiments are shown in Fig. 4(a), (b) and (c). Langmuir, Freundlich, and Dubinin-Radushkevich isotherm constants for the adsorption of $\mathrm{MB}$ by corncob are shown in Table 3 According to the value of $\mathrm{R}^{2}$, the adsorption isotherm study indicated that the Langmuir isotherm model fitted better than the Freundlich isotherm model. This indicates that the adsorption process is more monolayer in nature [29]. The maximum adsorption of $\mathrm{MB}$ from the Langmuir equation was found to be 417.12 $\mathrm{mg} / \mathrm{g}$. The average adsorption energy value obtained from the Dubinin-Radushkevich isotherm model indicated physical adsorption or chemical adsorption of MB by corncobs. In general, the adsorption energy is 1 to $8 \mathrm{~kJ} / \mathrm{mol}$ for physical adsorption and 20 to $40 \mathrm{~kJ} / \mathrm{mol}$ for chemical adsorption [30]. In this study, the adsorption energy of $\mathrm{MB}$ was found to be $3.352 \mathrm{~kJ} / \mathrm{mol}$

Table 3. Comparison of the Maximum Adsorption Capacity of MB Dye onto Agricultural Waste Adsorbents

\begin{tabular}{|c|c|c|}
\hline Adsorbent & $q_{m}(\mathrm{mg} / \mathrm{g})$ & Reference \\
\hline Walnut shell & 355.5 & [9] \\
\hline Rattan sawdust & 294.14 & [31] \\
\hline Waste apricot & 102.0 & [9] \\
\hline Palm kernel fiber & 95.4 & [25] \\
\hline Sunflower oil cake & 16.4 & [9] \\
\hline White pine sawdust & 102 & [28] \\
\hline Rice straw & 40.02 & [32] \\
\hline Garlic peel & 142.86 & [27] \\
\hline Tea waste & 85.16 & [33] \\
\hline Banana peel & 20.80 & [16] \\
\hline Orange Peel & 18.60 & [1] \\
\hline Rice husk & 40.59 & [19] \\
\hline Peanut hull & 68.03 & [8] \\
\hline Corncob & 417.12 & This study \\
\hline
\end{tabular}



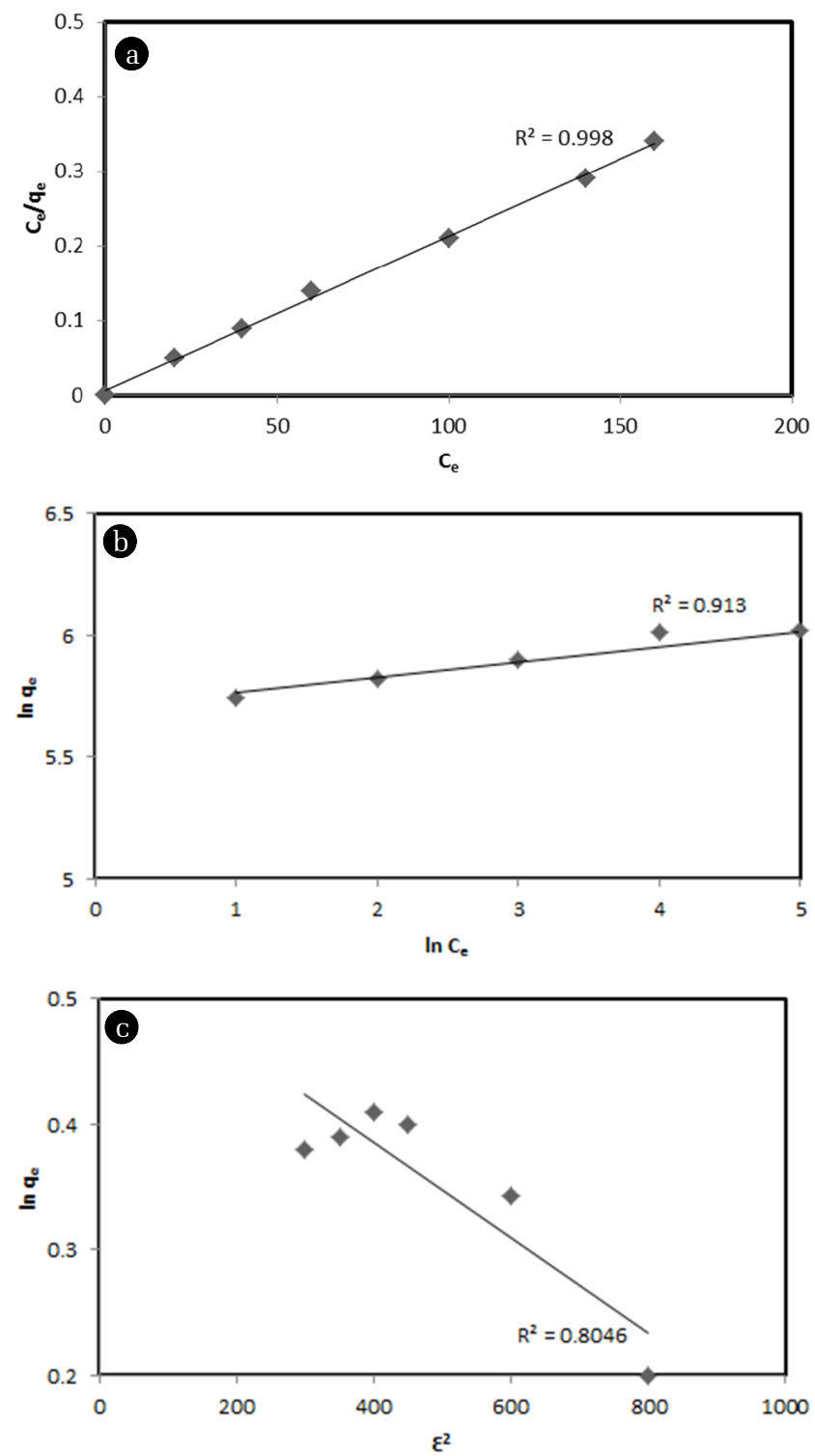

Fig. 4. Linearized (a) Langmuir, (b) Freundlich, and (c) D-R adsorption isotherms for the adsorption of $\mathrm{MB}$ (Corncob $=10 \mathrm{~g} / \mathrm{L}, \mathrm{MB}$ concentration $=0.005 \mathrm{~g} / \mathrm{L}$, Agitation $=150 \mathrm{rpm}$, Temperature $=30^{\circ} \mathrm{C}, \mathrm{pH}=6$ ).

(Table 2). Therefore, the adsorption process of MB by corncob is more influenced by physical adsorption. Moreover, the Freundlich exponent $n$ can be used to describe the intensity of adsorption. In this experiment, the value of $n$ was measured to be 3.108. Therefore, the MB adsorption process was closer to a physical process. According to general interpretation of $n$ and $1 / n$ value, $n=1$ indicates linear, $n>1$ indicates physical process, $n<1$ indicates chemical process, $1 / n=0.1$ to 0.5 indicates that adsorption process is magnificent, $1 / n=0.5$ to 1 indicates that the adsorption process is easy, and $1 / n \geq 1$ indicates that the adsorption process is difficult [30]. In this experiment, the value of $1 / n$ was found to be 0.32 , indicating that the MB dye adsorption process by corncob was very favorable and magnificent.

Results of comparison of the maximum adsorption capacity of MB dye by agricultural byproduct adsorbent are shown in Table 3. The maximum adsorption capacity of MB in the case of corncob used as an adsorbent in this study showed a higher adsorption amount than those of others. When agricultural byproducts were modified to remove the dyes by adsorption, removal efficiencies were relatively high than those of natural materials.

\subsection{Thermodynamic Interpretation}

Adsorption isotherm is affected by temperature. It represents thermodynamic equilibrium between $\mathrm{MB}$ adsorbed on the surface of corncob and $\mathrm{MB}$ in the aqueous solution. The effect of temperature on the capacity of corncob to adsorb MB was analyzed by adsorption isotherms of $\mathrm{MB}$ by corncob from aqueous solution at 20, 30, and $40^{\circ} \mathrm{C}$ with $\mathrm{pH}$ at 6 (Fig. 5(a)). Adsorption capacities were found to be 423,452 , and $490 \mathrm{mg} / \mathrm{g}$ at 20,30 and $40^{\circ} \mathrm{C}$, respectively. This tendency indicated that the adsorption capacity was increased by 1.07 and 1.16 times when the temperature was increased from $20^{\circ} \mathrm{C}$ to $30^{\circ} \mathrm{C}$ and from $30^{\circ} \mathrm{C}$ to $40^{\circ} \mathrm{C}$, respectively.

In order to investigate the effect of temperature change on adsorption capacity, equilibrium adsorption experiments were carried out at various solution temperatures to $293 \mathrm{~K}, 303 \mathrm{~K}$, and $313 \mathrm{~K}$. The value of $\Delta \mathrm{H}^{\circ}$ and $\Delta \mathrm{G}^{\circ}$ were calculated from slope
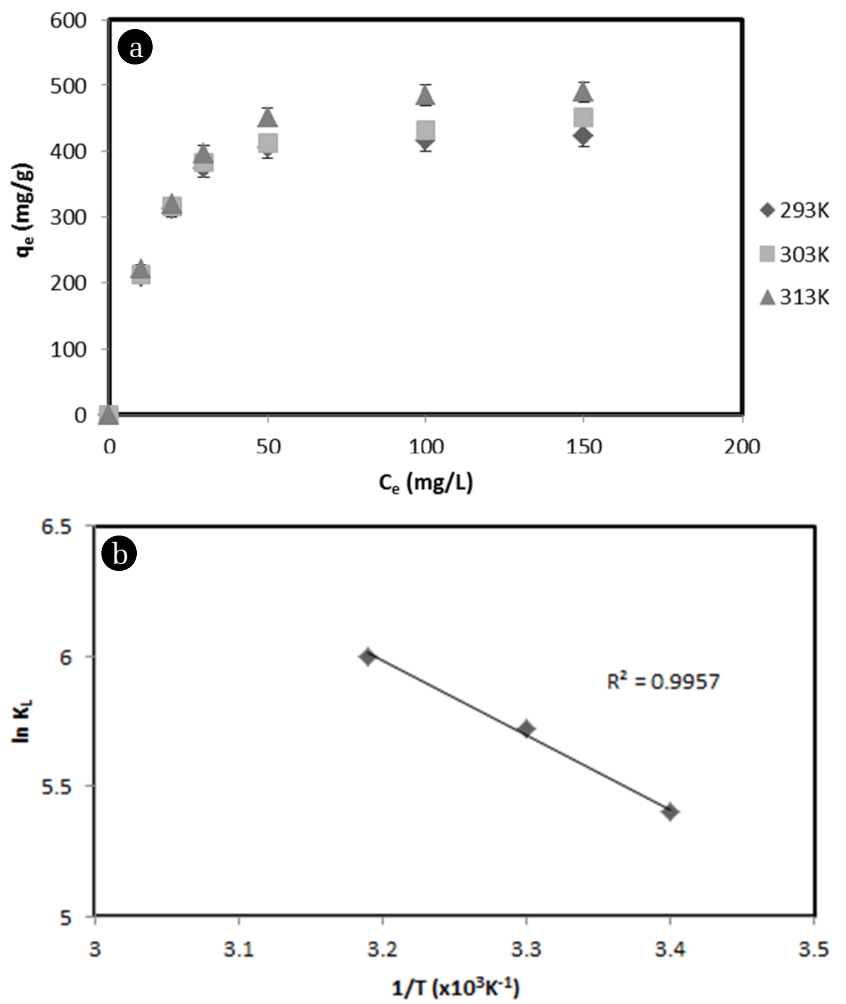

Fig. 5. (a) Adsorption isotherm of $M B$ at different temperatures, and (b) Application of van't Hoff equation. 
and intercept of the plot of $\operatorname{In} k_{L}$ versus $1 / \mathrm{T}$. Change in Gibbs free energy was calculated by using equation. Results are shown in Fig. 5(b). Calculated thermodynamic parameters for the removal of MB by corncob are shown in Table 2. Gibbs free energy is -20 to $0 \mathrm{~kJ} / \mathrm{mol}$ for physical adsorption and -80 to $-400 \mathrm{~kJ} / \mathrm{mol}$ for chemical adsorption [30]. In adsorption experiments of this study, the value of $\Delta \mathrm{G}^{\circ}$ was about -13.41 to $-16.58 \mathrm{~kJ} / \mathrm{mol}$, which fell in the range of physical adsorption process. In addition, $\Delta \mathrm{G}^{\circ}$ was negative, indicating that the adsorption process was spontaneous in nature. The positive value of $\Delta \mathrm{H}^{\circ}$ at all temperature indicated that the adsorption of $\mathrm{MB}$ dye by corncob was endothermic in nature. This might be due to the strong adsorptive force between the surface of the corncob and the MB dye molecule. In endothermic process, the adsorption equilibrium can be increased by raising the temperature. The value of $\Delta \mathrm{H}^{\circ}$, an important point in physical or chemical adsorption process, was measured to be $18.12 \mathrm{~kJ} / \mathrm{mol}$. Generally, if $\Delta \mathrm{H}^{\circ}$ value is less than 40 , it is interpreted as physical adsorption [21]. In addition, the affinity of $\mathrm{MB}$ dye for corncob is good because $\Delta S^{\circ}$ is positive at 0.1057 $\mathrm{J} / \mathrm{mol} \cdot \mathrm{K}$. The positive value of $\Delta \mathrm{S}^{\mathrm{o}}$ indicates that $\mathrm{MB}$ dye concentration is increased in the solid-liquid interface, thereby decreasing $\mathrm{MB}$ dye concentration on the surface of corncob. Moreover, the positive value of $\Delta \mathrm{S}^{\circ}$ might be featured that adsorbate molecules gets at least one degree of freedom when it loses adsorption on the corncob. It also validates that randomness at the solid-liquid interface is increased during the adsorption process. Taking all results into consideration, $\mathrm{MB}$ removal using corncob is more likely to be performed by physical adsorption using the force of van der Waals rather than by chemical adsorption.

\section{Conclusions}

Batch adsorption experiments were carried out to remove $\mathrm{MB}$ in water by using corncob, an agricultural waste, as an adsorbent to optimize the influence of parameters such as initial MB dye concentration, $\mathrm{pH}$, adsorbent dosage, and temperature on $\mathrm{MB}$ removal. Corncob bioadsorbent successfully removed $\mathrm{MB}$ dye in the aqueous solution (up to $96 \%$ of $\mathrm{MB}$ ) with the following optimal parameters: Temperature $30^{\circ} \mathrm{C}$; $\mathrm{pH}>6$; corncob 10 $\mathrm{g} / \mathrm{L}$; and $\mathrm{MB}$ concentration $<0.005 \mathrm{~g} / \mathrm{L}$. These results indicate that corncob can be a promising bioadsorbent due to its high efficiency and low dose requirements. The maximum adsorption of $\mathrm{MB}$ from the Langmuir equation was found to be $417.1 \mathrm{mg} / \mathrm{g}$. The adsorption kinetic study was best described by pseudo-second-order kinetic model. This indicates that the adsorption process is controlled by physical adsorption. In addition, the value of $1 / \mathrm{n}$ was 0.32 . This indicates that the $\mathrm{MB}$ dye adsorption process onto corncob is very favorable and magnificent. In the adsorption process, external mass transfer occurs in the early stage. Internal particle diffusion process then proceeds. The negative $\Delta \mathrm{G}^{\circ}$ value indicates that the adsorption is feasible and spontaneous. The positive $\Delta \mathrm{H}^{\circ}$ and $\Delta \mathrm{S}^{\circ}$ values indicate the endothermic nature of the adsorption and the affinity of corncob for $\mathrm{MB}$ adsorption, respectively. Based on these experimental results, we conclude that corncob is a cheap, efficient, and commercially viable new eco-friendly adsorbent for adsorbing and removing MB dye.

\section{Acknowledgments}

This study was supported by a grant (2016005271) of the Basic Science Research Program through the National Research Foundation of Korea (NRF) funded by the Ministry of Education, Science and Technology, Republic of Korea.

\section{References}

1. Annadurai G, Juang RS, Lee DJ. Use of cellulose-based wastes for adsorption of dyes from aqueous solutions. J. Hazard. Mater. 2002;B92:263-274.

2. Ahmed MJ, Dhedan SK. Equilibrium isotherms and kinetics modeling of methylene blue adsorption on agricultural wastes-based activated carbons. Fluid Phase Equilib. 2010;317:9-14.

3. Lee S, Ong S. Oxalic acid modified rice hull as a sorbent for methylene blue removal. APCBEE Procedia 2014;9:165-169.

4. Choi HJ, Kim KH. Parametric study a dyeing wastewater treatment by modified sericite. Environ. Technol. 2016;37: 2572-2579.

5. Peydayesh M, Kelishami AR. Adsorption of methylene blue onto Platanus orientalis leaf powder: Kinetic, equilibrium and thermodynamic studies. J. Ind. Eng. Chem. 2015;21: 1014-1019.

6. Yagub MT, Sen TK, Afroze S, Ang HM. Dye and its removal from aqueous solution by adsorption: A review. Adv. Colloid Interf. Sci. 2014;209:172-184.

7. Ebrahimian A, Saberikhah E, Badrouh M, Emami MS. Alkali treated foumanat tea waste as an efficient adsorbent for methylene blue adsorption from aqueous solution. Water Resour. Ind. 2014;6:64-80.

8. Gong R, Li M, Yang C, Sun Y, Chen J. Removal of cationic dyes from aqueous solution by adsorption on peanut hull. J. Hazard. Mater. 2005;B121:247-250.

9. Rafatullah M, Sulaiman O, Hashim R, Ahmad A. Adsorption of methylene blue on low-cost adsorbents: A review. J. Hazard. Mater. 2010;177:70-80.

10. Balarak D, Jaafari J, Hassani G, et al. The use of low cost adsorbent (Canola residues) for the adsorption of methylene blue from aqueous solution: Isotherm, kinetic and thermodynamic studies. Colloid Interf. Sci. Commun. 2015;7:16-19.

11. Kamel HA, Jibouri A, Wu J, Upreti SR. Continuous ozonation of methylene blue in water. J. Water Process Eng. 2015;8: 142-150.

12. Kumar PS, Abhinaya RV, Arthi V, Gayathrilashmi K, Priyadharshini M, Sivanesan S. Adsorption of methylene blue dye onto surface modified cashew nut shell. Environ. Eng. Manag. J. 2014;13:545-556.

13. Sych NV, Trofymenko SJ, Poddubnaya OI, et al. Porous structure and surface chemistry of phosphoric acid activated carbon from corncob. Appl. Surf. Sci. 2012;261:75-82.

14. Abdelfattah I, Ismail AA, Sayed FA, Almedolab A, Aboeloghait KM. Biosorption of heavy metals ions in real industrial wastewater using peanut husk as efficient and cost effective adsorbent. Environ. Nanotechnol. Monit. 
Manag. 2016;6:176-183.

15. Pirbazari AE, Saberikhah E. $\mathrm{Fe}_{3} \mathrm{O}_{4}-$ wheat straw: Preparation, characterization and its application for methylene blue adsorption. Water Res. Ind. 2014;7-8:23-37.

16. Pereira H, Carvalho D, Huang J, et al. Improvement of methylene blue removal by electrocoagulation/banana peel adsorption coupling in a batch system. Alexandria Eng. J. 2015;54:777-786.

17. Argun ME, Guclu D, Karatas M. Adsorption of reactive blue 114 dye by using a new adsorbent: pomelo peel. J. Ind. Eng. Chem. 2014;20:1079-1084.

18. Low LW, Teng TT, Morad N, Azahari B. Studies on the adsorption of methylene blue dye from aqueous solution onto low-cost tartaric acid treated bagasse. APCBEE Procedia 2012;1:103-109.

19. Vadivelan V, Kumar KV. Equilibrium, kinetics, mechanism, and process design for the sorption of methylene blue onto rice husk. J. Colloid Interf. Sci. 2005;286:90-100.

20. Kumar PS, Abhinaya RV, Lashmi KG, Arthi V, Pavithra R, Sathyaselvabala V. Adsorption of methylene blue dye from aqueous solution by agricultural waste: Equilibrium, thermodynamics, kinetics, mechanism and process design. Colloid J. 2011;73:651-661.

21. Kumar PS, Fernando PSA, Ahmed RT, et al. Effect of temperature on the adsorption of methylene blue dye onto sulphuric acid-treated orange peel. Chem. Eng. Commun. 2014;201: 1526-1547.

22. Kumar PS, Sivaranjanee R, Vinothini U, Raghavi M, Rajasekar $\mathrm{K}$, Ramakrishnan K. Adsorption of dye onto raw and surface modified tamarind seeds: Isotherms, process design, kinetics and mechanism. Desalin. Water Treat. 2014;52:2620-2633.

23. Gupta VK, Nayak A. Cadmium removal and recovery from aqueous solutions by novel adsorbents prepared from orange peel and $\mathrm{Fe}_{2} \mathrm{O}_{3}$ nanoparticles. Chem. Eng. J. 2012;80:81-90.

24. Nwadiogbu JO, Ajiwe VIE, Okoye PAC. Removal of crude oil from aqueous medium by sorption on hydrophobic corncobs: Equilibrium and kinetics studies. J. Taibah Univ. Sci. 2016;10:56-63.

25. El-Sayed G, Yehia MM, Asaad AA. Assessment of activated carbon prepared from corncob by chemical activation with phosphoric acid. Water Res. Ind. 2014;7-8:66-75.

26. Azubuike CP, Okhamafe AO. Physicochemical, spectroscopic and thermal properties of microcrystalline cellulose derived from corncobs. Int. J. Recycl. Org. Waste Agr. 2012;1:9-11

27. Hameed BH, Ahmad AA. Batch adsorption of methylene blue from aqueous solution by garlic peel, an agricultural waste biomass. J. Hazard. Mater. 2009;164:870-875.

28. Salazar-Rabage JJ, Leyva-Ramos R, Rivera-Utrilla J, Ocampo-Perez R, Cerino-Cordova FJ. Biosorption mechanism of methylene blue from aqueous solution onto white pine (Pinus durangensis) sawdust: Effect of operating conditions. Sustain. Environ. Res. 2017;7:32-40.

29. Yao YJ, Xu FF, Chen M, Xu ZX, Zhu ZW. Adsorption behavior of methylene blue on carbon nanotubes. Bioresour. Technol. 2010;101:3040-3046.

30. Ali RM, Hamad HA, Hussein MM, Malash GF. Potential of using green adsorbent of heavy metal removal from aqueous solutions: Adsorption kinetics, isotherm, thermodynamic, mechanism and economic analysis. Ecol. Eng. 2016;91: 317-332.

31. Hameed BH, Ahmad AL, Latiff KNA. Adsorption of basic dye (methylene dye) onto activated carbon prepared from rattan sawdust. Dyes Pigm. 2007;75:143-146.

32. Zhang S, Wang Z, Zhang Y, Pan H, Tao L. Adsorption of methylene blue on organosolv lignin from rice straw. Procedia Environ. Sci. 2016;31:3-11.

33. Uddin MT, Islam MA, Mahmud S, Rukanuzzaman M. Adsorptive removal of methylene blue by tea waste. J. Hazard. Mater. 2009;164:53-60. 